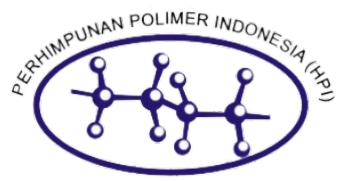

\title{
Gel Komposit Starch-Graft-Acrylic Acid/Bentonite (St-g-AA/B): Sintesis, Karakterisasi dan Kapasitas Penyerapan
}

\author{
Trias Ayu Laksanawatia, Prida Novarita Trisantia ${ }^{2}$ Sumarno $^{a}{ }_{\dagger}$
}

\begin{abstract}
Gel komposit Starch-Graft-Acrylic Acid/Bentonite (St-g-AA/B) merupakan polimer tiga dimensi yang ramah lingkungan serta dapat menyerap air dalam jumlah besar. Pati dan bentonit merupakan bahan baku alami untuk sintesis gel komposit St-g-AA/B. Acrylic acid yang digunakan telah dinetralisasi $40 \%$ bagian dengan $\mathrm{NaOH}$. Material gel komposit St-g-AA/B disintesis dengan metode kopolimerisasi graft. Proses kopolimerisasi menggunakan larutan potasium persulfat (KPS) sebagai inisiator dan larutan $\mathrm{N}^{\prime} \mathrm{N}$-Methylenebisacrylamide (MBA) sebagai bahan jaringan. MBA dilarutkan terlebih dahulu untuk menghindari aglomerasi dan agar cepat tersebar dalam campuran saat reaksi berlangsung. Dilakukan penambahan bentonit di awal proses reaksi agar lebih terdistribusi merata pada jaringan. Proses sintesa dilakukan pada suhu $70{ }^{\circ} \mathrm{C}$ selama dua jam dengan aliran gas nitrogen. Produk yang dihasilkan dikeringkan sampai beratnya konstan. Dari hasil penelitian, diperoleh kapasitas penyerapan air maksimal yaitu 202,67 $\mathrm{g} \mathrm{g}^{-1}$ dan $153 \mathrm{~mL} \mathrm{~mL}^{-1}$ dengan konsentrasi bahan jaringan 1,5\%wt dan konsentrasi bentonit 2\%wt acrylic acid. Produk dikarakterisasi dengan Fourier Transform Infrared Spectroscopy (FTIR) dan X-ray Diffraction (XRD). Dari hasil karakterisasi, diketahui bahwa gel komposit St-g-AA/B berhasil disintesis dengan dibuktikan tidak adanya ikatan $\mathrm{C}$ rangkap dua pada acrylic acid dan kristalinitas pati berkurang.
\end{abstract}

Composite gels Starch-Graft-Acrylic Acid/Bentonite (St-g-AA/B) are three-dimensional hydrophilic polymer networks that are eco-friendly and can absorb large amounts of water. Starch and bentonite were utilized as raw material for the synthesis of composite gels St-g-AA/B. Acrylic acid that neutralized $40 \%$ parts with $\mathrm{NaOH}$ was used in the copolymerization process. In this study, composite gels St-g-AA/B was successfully synthesized by graft copolymerization. The graft copolymerization process uses potassium persulfate (KPS) as a free radical initiator and $\mathrm{N}^{\prime} \mathrm{N}$-Methylenebisacrylamide (MBA) solution as a crosslinker. MBA is dissolved first to avoid agglomeration and to quickly spread in the mixture when the reaction takes place. The addition of bentonite at the beginning of the reaction process is more evenly distributed on the polymer network. The synthesis process at $70^{\circ} \mathrm{C}$ for two hours with purging nitrogen gas. The product is dried until constant weight. Based on the result, show that composite gel had an optimum MBA value of $1.5 \%$ wt and bentonite concentration $2 \% w t$ acrylic acid with water absorbency obtained were $202.67 \mathrm{~g} \mathrm{~g}^{-1}$ and $153 \mathrm{~mL} \mathrm{~mL}^{-1}$. The product was characterized by Fourier Transform Infrared Spectroscopy (FTIR) and X-ray Diffraction (XRD). From the results of the characterization, it was found that the composite gel St-g-AA/B was successfully synthesized by the absence of $C$ double bonds on acrylic acid and reduced starch crystallinity.

28 December 2018

Published

28 June 2019

Kata kunci: Bahan jaringan, bentonit, gel komposit, kapasitas penyerapan.

\section{Pendahuluan}

Gel komposit merupakan jaringan polimer hidrofilik tiga dimensi yang dapat menyerap sejumlah besar air dengan daya serap mulai dari 10 hingga 1000 kali dari bobot awalnya dan ramah lingkungan. ${ }^{1}$ Dengan kemampuan menyerap dan menyimpan air, gel komposit dapat dimanfaatkan secara luas antara lain dalam bidang pertanian, farmasi, biomedis, drug release, diapers. Polimer sintetis dengan bahan jaringan (crosslinker) dan biopolimer umumnya digunakan dalam pembuatan gel komposit. Penggunaan polimer sintetis untuk gel komposit yang dibuat dari bahan jaringan $\left(\mathrm{N}^{\prime} \mathrm{N}-\right.$ methylenebisacrylamide atau kromium triasetat) tergantung bahan baku terbarukan. Biopolimer (xhantan gum) telah terbukti

\footnotetext{
a. Departemen Teknik Kimia, Institut Teknologi Sepuluh Nopember, Kampus ITS Sukolilo, Surabaya 60111, Indonesia

+ Corresponding author: onramus@chem-eng.its.ac.id.
}

mampu menyerap air dalam jumlah yang besar, akan tetapi harganya mahal. Oleh karena itu, perlu dilakukan modifikasi struktur polimer alami dengan polimer sintetis.

Kopolimerisasi merupakan metode untuk memodifikasi struktur polimer alami sehingga memiliki sifat yang cocok sebagai polimer gel. Kopolimer graft dari bahan-bahan tersebut dan sejenisnya memiliki struktur jaringan hidrofilik tiga dimensi. Starch sangat potensial digunakan sebagai polimer alami dalam pembuatan polimer gel karena tersedia melimpah, murah serta ramah lingkungan (biodegradable). Bentonit yang disusupkan pada polimer gel dapat berguna untuk memperbaiki sifat dari polimer gel seperti memiliki kapasitas penyerapan air yang tinggi. ${ }^{2}$ Ren dkk (2012) melakukan penelitian tentang pembuatan polimer gel menggunakan starch yang tergelatinasi sebagai backbone yang ditambahkan KPS sebagai inisiator di tahap awal. Kemudian ditambahkan acrylic acid dan acrylamide dan bahan jaringan $\mathrm{N}$ 'N-methylenebisacrylamide untuk membentuk jaringan tiga dimensi. Dari 
hasil penelitian didapatkan kapasitas penyerapan terhadap air sebesar $699 \mathrm{~g} \mathrm{~g}^{-1} .^{3}$ Kulkarni dkk (2014) melakukan penelitian tentang pembuatan polimer gel dari starch yang tergelatinasi ditambahkan acrylic acid, bentonit (untuk meningkatkan daya serap air), dan menggunakan $\mathrm{N}^{\prime} \mathrm{N}$-methylenebisacrylamide sebagai bahan jaringan. Pada tahap akhir ditambahkan inisiator KPS untuk memulai reaksi grafting. Penelitian ini melaporkan bahwa daya serap air maksimal $725 \mathrm{~g} \mathrm{~g}^{-1}$ dan daya serap maksimal dalam larutan garam $0,2 \%$ sebesar $640 \mathrm{~g} \mathrm{~g}^{-1}$. Dari penelitian tersebut membuktikan bahwa dengan penambahan bentonit dalam jaringan tiga dimensi memberikan peningkatan kapasitas penyerapan air. ${ }^{4}$

Proses polimerisasi untuk mendapatkan sifat tersebut selain dipengaruhi oleh penambahan bentonit juga dipengaruhi oleh komposisi bahan baku serta pengaturan tahap polimerisasinya, sehingga perlu dilakukan penelitian lebih lanjut untuk memperoleh polimer gel yang memiliki sifat lebih baik. Pada penelitian ini akan dilakukan sintesis polimer gel komposit dengan menggunakan modifikasi kedua tahap proses polimerisasi di atas dan dilakukan uji terhadap produk polimer gel komposit yaitu uji kapasitas penyerapan air berdasarkan perbandingan berat dan volume.

\section{Metode Percobaan}

\section{Alat dan Bahan}

Starch (powder, PT. Sungai Budi, Jakarta, Indonesia), acrylic acid (AA, chemically pure, Shanghai Wulian Chemical Factory, Shanghai, China), N'N-methylenebisacrylamide (MBA, analytical grade, Promega Corporation, USA), potasium persulfat (KPS, analytical grade, Merck KGaA, Darmstadt, Germany), sodium hydroxide ( $\mathrm{NaOH}$, analytical grade, Merck KGaA, Darmstadt, Germany), nitrogen gas ( $\mathrm{N}_{2}$ didapatkan dari Samator Gas, Sidoarjo, Indonesia) adalah high purity nitrogen, bentonit (powder, Research Unit for Mineral technology, LIPI, Indonesia). Semua bahan terlebih dahulu dilarutkan dalam air suling. Peralatan dari sintesis gel komposit Stg-AA/B dapat dilihat pada Gambar 1.

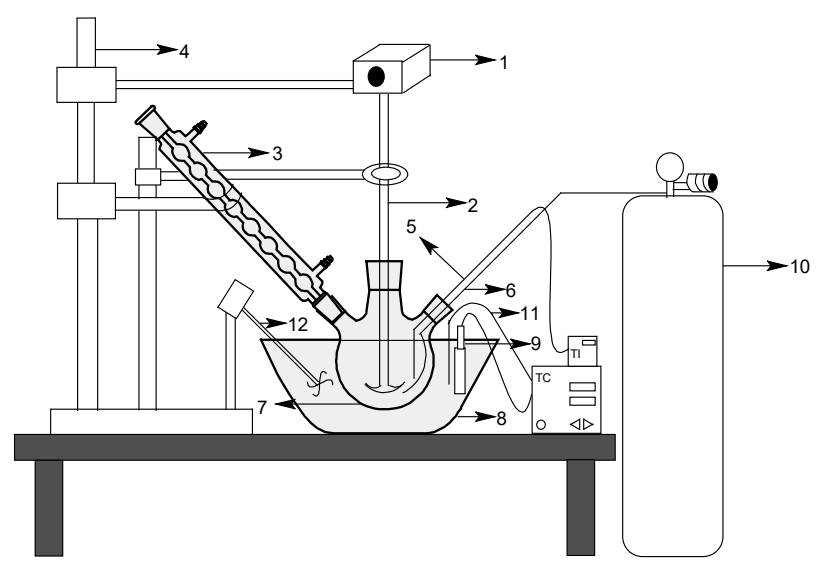

Gambar 1. Peralatan sintesis St-g-AA/B.

Keterangan :
1. Motor pengaduk
7. Reaktor polimerisasi
2. Pengaduk
8. Gliserin bath
3. Kondenser
9. Heater
4. Statif dan Klem
10. Tabung $\mathrm{N}_{2}$
5. Indikator suhu
11. Pengatur suhu
6. $\mathrm{N}_{2}$ inlet
12. Pengaduk gliserin

\section{Cara Kerja}

Larutan pati $10 \%$ dimasukkan dalam labu leher tiga sebagai reaktor yang dilengkapi dengan pengaduk, kondenser, $\mathrm{N}_{2}$ inlet dan pengontrol suhu. Larutan pati tersebut dipanaskan sampai suhu $95^{\circ} \mathrm{C}$ selama 30 menit. Larutan pati didinginkan sampai suhu ruang. Ditambahknan monomer acrylic acid yang telah dinetralkan dengan $\mathrm{NaOH} 40 \%$ (derajat netralisasi) kemudian ditambahkan bentonit. Campuran dipanaskan sampai suhu $60^{\circ} \mathrm{C}$ disertai pengadukan dan dialiri gas nitrogen. Larutan potasium persulfat (KPS) sebagai inisiator ditambahkan, kemudian MBA yang telah dilarutkan dalam air suling ditambahkan dalam campuran. Suhu dinaikkan sampai $70^{\circ} \mathrm{C}$ dan reaksi dilakukan selama 2 jam. Setelah itu produk di-dinginkan sampai suhu ruang. Produk dicuci dengan etanol dan air suling kemudian dikeringkan dalam oven pada suhu $60{ }^{\circ} \mathrm{C}$ sampai beratnya konstan. Produk yang kering dihaluskan sampai ukuran 40 80 mesh. Untuk mengetahui kapasitas penyerapan air dalam perbandingan berat dan volume dilakukan perendaman produk kering dalam air suling selama 4 jam, sehingga dapat diketahui berat awal dan berat akhir produk St-g-AA/B setelah menyerap air. Kapasitas penyerapan air dalam perbandingan berat dan volume dapat dihitung dengan persamaan berikut:

kapasitas penyerapan air $\left(\mathrm{mL} \mathrm{mL}^{-1}\right)=\frac{\left(\mathrm{V}^{\prime}-\mathrm{V}\right)}{\mathrm{V}}$

di mana $V^{\prime}$ adalah volume gel komposit St-g-AA/B setelah proses penyerapan air $(\mathrm{mL})$ dan $V$ adalah volume gel komposit St-g-AA/B awal $(\mathrm{mL})$.

kapasitas penyerapan $\left(\mathrm{g} \mathrm{g}^{-1}\right)=\frac{\mathrm{W}^{\prime}-\mathrm{W}}{\mathrm{W}}$

di mana $W^{\prime}$ adalah berat gel komposit St-g-AA/B setelah proses penyerapan air ( $g$ ) dan $W$ adalah berat gel komposit St-g-AA/B awal (g). Produk gel komposit Starch-Graft-Acrylic Acid/Bentonite (St-gAA/B) yang telah disintesis, dikarakterisasi dengan menggunakan alat Fourier Transform Infrared (FTIR) dan X-ray Diffraction (XRD).

\section{Hasil dan Pembahasan}

Spektrum FTIR untuk produk gel komposit St-g-AA/B menunjukkan puncak bilangan gelombang $\mathrm{O}-\mathrm{H}$ serta $\mathrm{N}-\mathrm{H}$ yang lebar dan kuat pada $3271,95 \mathrm{~cm}^{-1}$, puncak gelombang $\mathrm{C}=0$ pada $1701,46 \mathrm{~cm}^{-1}$, puncak gelombang ikatan $\mathrm{N}-\mathrm{H}$ pada $1551,61 \mathrm{~cm}^{-1}$, serta puncak gelombang ikatan Si-O berada pada bilang gelombang 1015,08 $\mathrm{cm}^{-1}$. Dari Gambar 2 dapat dibandingkan spektra FTIR keempat bahan dengan produk gel komposit St-g-AA/B di mana terlihat beberapa puncak pada titik yang sama yang menandakan adanya ikatan yang sama. Ikatan ini membuktikan bahwa starch, acrylic acid dan MBA telah terdapat pada produk St-g-AA/B. Selain itu hasil spektra FTIR produk tidak ditemukan adanya bilangan gelombang $1634,46 \mathrm{~cm}^{-1}$ yang menyatakan adanya keberadaan ikatan $\mathrm{C}=\mathrm{C}$ pada produk. Hal tersebut membuktikan bahwa reaksi kopolimerisasi graft berhasil dilakukan dan terjadi pada karbon rangkap dua pada monomer acrylic acid. Pada produk St-g-AA/B juga terdapat puncak pada bilangan gelombang $1015,08 \mathrm{~cm}^{-1}$ menunjukkan adanya ikatan $\mathrm{Si}-\mathrm{O}$ yang dimiliki bentonit terdapat pada produk gel komposit St-g-AA/B, hal ter- 
sebut menandakan bahwa bentonit tidak hanya terjebak pada jaringan polimer tiga dimensi melainkan juga berikatan dengan gugus karboksil pada acrylic acid.

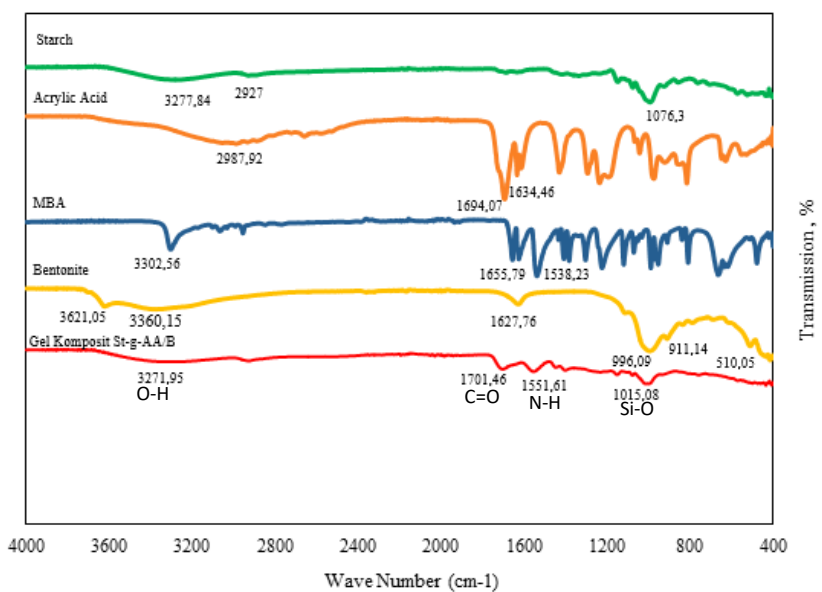

Gambar 2. Spektrum FTIR untuk (a) Starch, (b) Acrylic acid, (c) MBA, (d) Bentonit dan (e) St-g-AA/B.

Pada penelitian ini analisis XRD dilakukan untuk mengetahui fasa terbentuk pada gel komposit St-g-AA/B pada sudut hamburan $10^{\circ}-80^{\circ}$. Pola difraksi yang terbentuk pada starch bisa dilihat pada Gambar 3(a). Dari informasi sudut hamburan dapat dilihat bahwa starch memiliki beberapa puncak tajam pada sudut $2 \theta=15,17^{\circ}$; $17,95^{\circ} ; 18,31^{\circ}$ dan $22,91^{\circ}$. Pada gambar 3 (a) juga ditemukan puncak tidak tajam (melebar) yang menunjukkan sifat amorf. Hal ini menunjukkan bahwa starch memiliki struktur semikristalin. Menurut Zhang Genyi dkk (2006) starch terdiri dari struktur kristal dan amorf. ${ }^{5}$ Bagian kristal dibentuk oleh amilopektin heliks ganda. Sementara struktur amorf dibentuk oleh titik percabangan (ikatan 1,6) amilopektin, amilopektin rantai panjang dan amilosa. Sedangkan pada gambar 3(b) menunjukkan pola difraksi yang terbentuk pada bentonit. Dari gambar tersebut dapat dilihat bahwa bentonit memiliki beberapa puncak tajam pada sudut $2 \theta=20,95^{\circ}$; $22,39^{\circ} ; 34,99^{\circ}$ dan $35,92^{\circ}$.

Sementara hasil XRD pada gel komposit St-g-AA/B (Gambar 3(c)) menunjukkan bahwa gel komposit memiliki struktur amorf. Hal tersebut terlihat dari sudut hamburan bahwa pola difraktogram untuk gel komposit St-g-AA/B memiliki puncak tidak tajam dan sudut sedikit melebar. Sementara itu didukung dengan tidak lagi muncul puncak yang tajam pada starch yang menyatakan adanya amilosa dan amilopektin dalam pola XRD produk gel komposit St-g-AA/B yang berarti bahwa kristalinitas starch berkurang dalam produk St-gAA/B. Hal tersebut terjadi karena adanya reaksi kopolimerisasi grafting yaitu saat polyacrylic acid yang dicangkokkan ke dalam makromolekul starch, sehingga menghasilkan kristalisasi starch yang lebih rendah pada gel komposit St-g-AA/B. Selain itu puncak tajam pada bentonit tidak muncul dalam pola XRD gel komposit Stg-AA/B. Pola XRD dari produk St-g-AA/B menunjukkan puncak luas yang lemah pada $2 \theta=21,19^{\circ}$ karena amorfnya struktur produk gel komposit St-g-AA/B dengan low crystallinity. Kehadiran puncak tersebut terkait dengan bentonit dalam pola XRD untuk produk. Hasil XRD menunjukkan bahwa bentonit tersebar secara fisik dalam jari- ngan produk gel komposit St-g-AA/B dan juga bentonit dapat berikatan kimia dengan gugus karboksil pada acrylic acid.

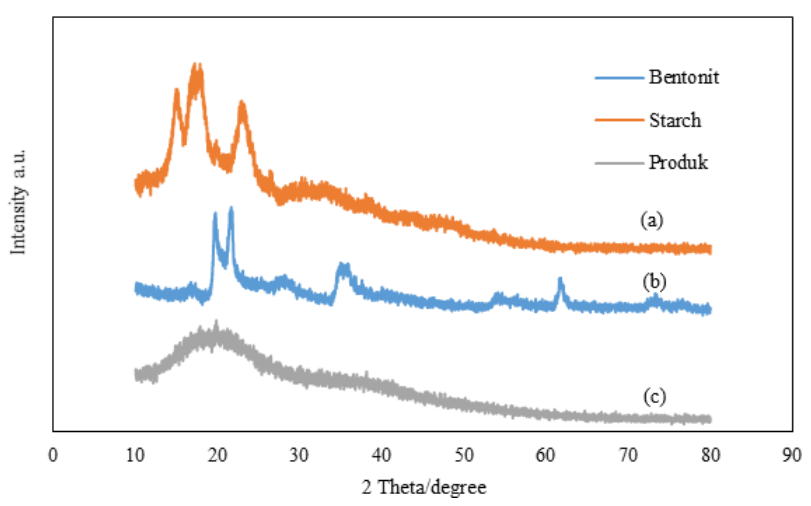

Gambar 3. Kurva XRD (a) Strach, (b) Bentonit dan (c) St-g-AA/B.

Pengaruh konsentrasi bahan jaringan (MBA) terhadap kapasitas penyerapan air gel komposit St-g-AA/B dipelajari dengan memvariasikan konsentrasi MBA dari $0,5 \%$ sampai $2 \%$ wt monomer acrylic acid. Dapat dilihat pada gambar 4. Kapasitas penyerapan air meningkat dengan meningkatnya konsentrasi bahan jaringan $\mathrm{N}^{\prime} \mathrm{N}-$ methylenebisacrylamide (MBA) dari 0,5-1,5\%wt acrylic acid. Selanjutnya kapasitas penyerapan air mengalami penurunan saat konsentrasi crosslinker dinaikkan lebih lanjut dari 1,5-2\%wt acrylic acid. Kapasitas penyerapan air maksimum yaitu $200,19 \mathrm{~g} \mathrm{~g}^{-1}$ dan 147 $\mathrm{mL} \mathrm{mL}^{-1}$ saat konsentrasi bahan jaringan 1,5\%wt monomer acrylic acid. MBA adalah bahan jaringan sebagai agen pengikat silang yang membantu mengikat dua atau lebih makromolekul melalui ikatan kovalen untuk membentuk jaringan. Jaringan ini mencegah hancurnya struktur gel dan mampu menjebak sejumlah besar air di dalam jaringannya.

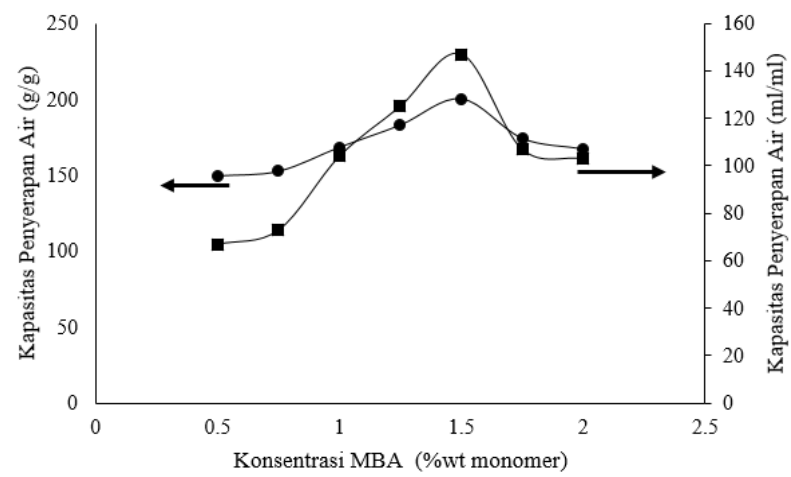

Gambar 4. Pengaruh konsentrasi MBA terhadap kapasitas penyerapan air.

Semakin besarnya konsentrasi bahan jaringan maka penyerapan kapasitas air semakin meningkat, namun ketika konsentrasi bahan jaringan diperbesar melebihi nilai optimumnya akan mengakibatkan penurunan kapasitas penyerapannya. Hal ini dimungkinkan karena gel komposit yang terbentuk memiliki struktur jaringan yang lebih rapat sehingga kemampuannya untuk menampung air tidak terlalu besar. Selain itu dengan semakin banyaknya bahan jaringan menyebabkan lebih banyak ikatan silang yang menyebabkan jaringan ikat semakin bertambah sehingga dapat menurunkan volume 
bebas dan menyebabkan kapasitas penyerapan terhadap air berkurang. Saat konsentrasi bahan jaringan rendah maka dihasilkan kapasitas penyerapan air yang rendah. Hal ini dikarenakan rendahnya kerapatan agen pengikat silang sehingga tidak mampu untuk mempertahankan air yang diserap dan polimer gel lebih bersifat mudah larut.

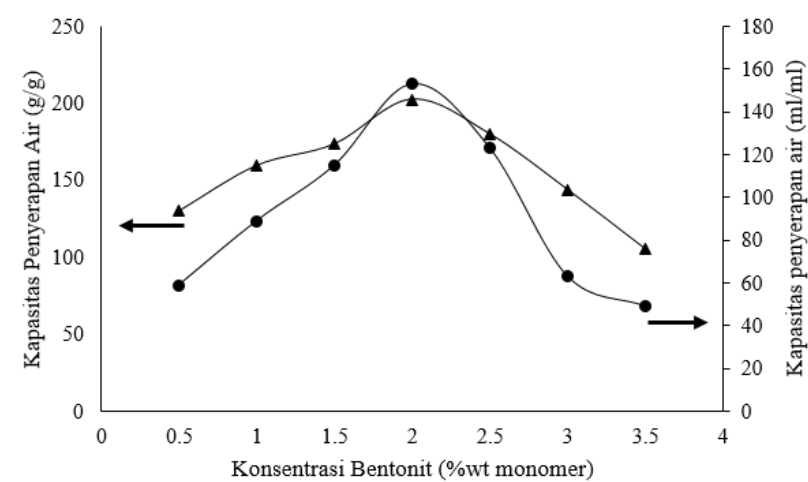

Gambar 5. Pengaruh konsentrasi bentonit terhadap kapasitas penyerapan air.

Gambar 5 menunjukkan bahwa kapasitas penyerapan air meningkat dengan meningkatnya konsentrasi bentonit. Kapasitas penyerapan air maksimum yaitu sebesar 202,67 $\mathrm{g} \mathrm{g}^{-1}$ dan $153 \mathrm{~mL}$ $\mathrm{mL}^{-1}$ pada saat konsentrasi bentonit $2 \%$ berat terhadap monomer acrylic acid. Kapasitas penyerapan air mengalami kenaikan dari konsentrasi $0,5 \%$ hingga konsentrasi $2 \%$ wt monomer acrylic acid. Sedangkan dari konsentrasi bentonit yang meningkat lebih lanjut dari 2\% hingga 3,5\%wt monomer acrylic acid, kapasitas penyerapan air mengalami penurunan. Partikel bentonit dalam jaringan gel komposit bertindak sebagai titik jaringan tambahan (gugus karboksilat pada polyacrylic acid bereaksi dengan gugus - $\mathrm{OH}$ pada permukaan bentonit) sehingga bentonit juga dapat menambah jaringan hidrofilik dalam jaringan polimer. Ketika jumlah konsentrasi bentonit rendah maka menghasilkan kapasitas penyerapan air yang rendah. Hal tersebut terjadi karena, kemampuan bentonit sebagai titik jaringan tambahan sehingga saat konsentrasi bentonit rendah hanya terdapat sedikit titik jaringan dan menyebabkan kemampuan gel komposit untuk menyerap dan mempertahankan air menjadi rendah. Saat jumlah konsentrasi bentonit diperbesar maka kapasitas penyerapan air menjadi meningkat, namun saat konsentrasi bentonit semakin diperbesar melebihi konsentrasi optimumnya menghasilkan penurunan kapasitas penyerapan. Hal tersebut dikarenakan semakin banyaknya partikel bentonit didalam jaringan polimer maka menyebabkan titik jaringan gel komposit menjadi semakin banyak dan rapat sehingga menyebabkan gel komposit bersifat kaku.

\section{Kesimpulan}

Gel komposit Starch-Graft-Acrylic Acid/Bentonite (St-g-AA/B) berhasil disintesis dengan kopolimerisasi cangkok menggunakan tahap proses pendekatan baru terhadap tahap yang telah diusulkan oleh Ren dkk (2012) dan Kukarni dkk (2014). Hasil penelitian menunjukkan bahwa gel komposit Starch-Graft-Acrylic Acid/Bentonite (St-g-AA/B) memiliki kapasitas penyerapan optimum pada jumlah bentonit $2 \%$ wt acrylic acid dengan kapasitas penyerapan air maksimal sebesar 202,67 $\mathrm{g} \mathrm{g}^{-1}$ dan $153 \mathrm{~mL} \mathrm{~mL}^{-1}$. Dari hasil karakterisasi produk dengan Fourier Transform Infrared Spectroscopy (FTIR) didapatkan bahwa pada produk gel komposit Starch-GraftAcrylic Acid/Bentonite (St-g-AA/B) ditemukan gugus-gugus dari material penyusunnya dan sudah tidak ditemukan adanya ikatan $\mathrm{C}=\mathrm{C}$ yang dimiliki oleh monomer acrylic acid pada produk St-g-AA/B.

\section{Ucapan Terima Kasih}

Ucapan terima kasih diberikan kepada pihak Lembaga Pengelola Dana Pendidikan (LPDP) sebagai pemberi bantuan dana penelitian kepada penulis dalam melakukan penelitian ini.

\section{Referensi}

1 A. Pourjavadi, S. Amini-Fazl, dkk, Optimization of synthetic conditions CMC-g-poly (acrylic acid)/Celite composite superabsorbent by Taguchi method and determination of its absorbency under load, eXPRESS Polymer Letters, 2007, 1(8), 488-494.

2 Syuhada, R. Wijaya, dkk, Modifikasi Bentonit (Clay) menjadi Organoclay dengan Penambahan Surfaktan, Jurnal Nanosains \& Nanoteknologi, 2009, 2(1).

3 Ren, H. Niu, Z. dkk, Comparison of Traditional Methods and Microwave Irradiation Method About Amylum/Acrylic Acid /Acrylamide Polymerization, IntechOpen, 2012.

4 P. Kulkarni, L. Kalwale, dkk, Synthesis and characterization of poly (acrylic acid) /Starch/Bentonite superabsorbent polymer composite, Research \& reviews In Polymer, 2014, 5(3), 96-101.

5 G. Zhang, M. Venkatachalam dan B.R. Hamaker, Structural Basis for the Slow Digestion Property of Native Cereal Starches, West Lafayette, Indiana. Biomacromolecules, 2006, 7, 3259-3266. 